\title{
Erratum to: Suicidal ideation and suicide attempts among asthma
}

\author{
Jae Ho Chung ${ }^{1}$, Sun-Hyun Kim² ${ }^{2 *}$ and Yong Won Lee ${ }^{1}$
}

\section{Erratum to: Ann Gen Psychiatry (2016) 15:35 DOI 10.1186/s12991-016-0122-2}

The article [1] has been updated. The previously published version contained some errors/mistakes. The word 'stroke' has been changed to 'asthma' in the following sections: (1) in Data Analysis, the word in the 5th, 6th and 8th lines of the first paragraph on page 3 has been modified; (2) in Results, the term in the 3rd and 4th lines of the first paragraph has been corrcted; (3) in Discussion, the word in the 9th line of the second paragraph on page 5 has been revised; (4) in Conclusion, the 8th line of the first paragraph on page 5 has been changed.

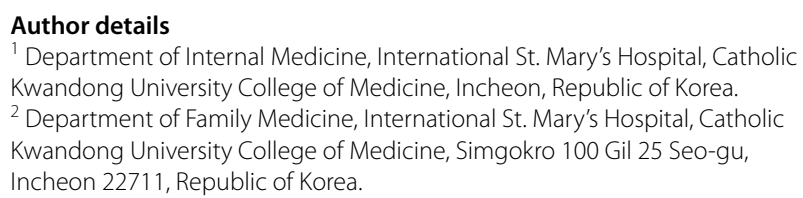

The online version of the original article can be found under doi:10.1186/s12991-016-0122-2.

Received: 29 December 2016 Accepted: 10 January 2017

Published online: 23 January 2017

\section{Reference}

1. Chung JH, Kim S-H, Lee YW. Suicidal ideation and suicide attempts among asthma. Ann Gen Psychiatry. 2016;15:35. doi:10.1186/ s12991-016-0122-2.

\footnotetext{
*Correspondence: sunhyun@yahoo.com

${ }^{2}$ Department of Family Medicine, International St. Mary's Hospital,

Catholic Kwandong University College of Medicine, Simgokro 100 Gil 25

Seo-gu, Incheon 22711, Republic of Korea

Full list of author information is available at the end of the article
} 